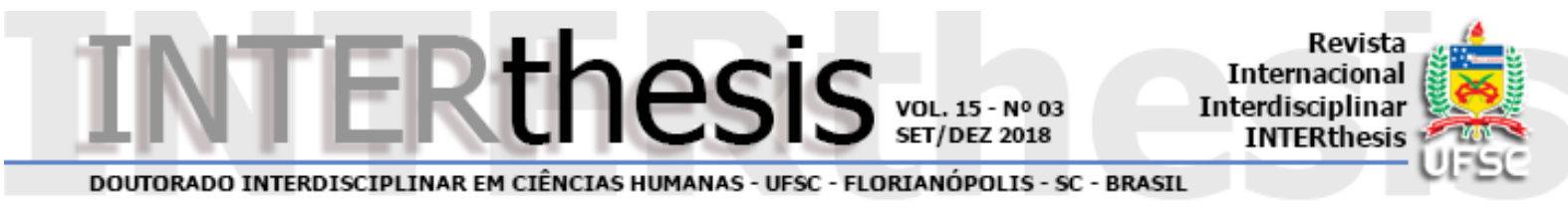

\title{
REFLEXÕES SOBRE O PODER MEDIADAS PELO EMPODERAMENTO DAS MULHERES NA CONDIÇÃO DE SUJEITO POLÍTICO
}

Maria Helena Santana $\mathrm{Cruz}^{1}$

Ana Paula Leite Nascimento ${ }^{2}$

Anabela Maurício de Santana ${ }^{3}$

\section{Resumo:}

Este artigo tem como objetivo refletir sobre o empoderamento das mulheres na condição de sujeito político, elemento fundamental para sua emancipação e participação ativa na sociedade. Com vistas a alcançar o objetivo proposto, desenvolveu-se uma pesquisa qualitativa de natureza bibliográfica em diálogo com vertentes do conceito de gênero, patriarcado e empoderamento das mulheres. $O$ empoderamento envolve um processo político para gerar compreensão dos complexos fatores que criam subordinação/exclusão das mulheres do mundo público/político e engendrar consciência sobre a reformulação/desconstrução dos atuais esquemas políticos e sociais da sociedade. Captamos, pois, que é preciso levar em conta as relações de poder entre homens e mulheres, e, desta maneira, buscar solucionar não somente condições concretas materiais das mulheres, senão também mudar as relações sociais de gênero na sociedade, construindo democracias com equidade de gênero.

Palavras-chave: Poder. Empoderamento. Gênero. Reconhecimento. Equidade.

\section{INTRODUÇÃO}

Através de textos de autores distintos da área das ciências sociais este artigo tem como objetivo refletir sobre o processo de empoderamento, ou empowerment, de mulheres, relacionado a uma vertente do conceito de participação compreendendo-a numa perspectiva crítica como mecanismo de ampliação dos espaços democráticos em que o cidadão percebe-se como uma unidade social que pode quebrar um sistema estabelecendo um diálogo com as formas de aquisição de poder e reconhecimento, e, as ações sobre os recursos, reformulação e

\footnotetext{
1 Doutora em Educação pela Universidade Federal da Bahia, Bahia, BA. Pós-Doutorado em Sociologia da Educação na Universidade Federal de Sergipe. Professora nos Programas de PósGraduação em Educação e Serviço Social na mesma universidade. Professora Emérita da Universidade Federal de Sergipe, São Cristovão, SE, Brasil. E-mail: helenacruz@uol.com.br

2 Doutoranda em Educação na Universidade Federal de Sergipe. Assistente Social do Instituto Federal de Educação, Ciência e Tecnologia de Sergipe, Lagarto, SE, Brasil E-mail: paulajcbrasil@yahoo.com.br

${ }^{3}$ Doutoranda em Educação pelo Programa de Pós-graduação em Educação da Universidade Federal de Sergipe. Professora Tutora do Centro de Educação Superior a Distância da Universidade Tiradentes. E-mail: anab.santana@hotmail.com
} 
desconstrução dos atuais esquemas que constroem a desigualdade nos aspectos políticos e sociais (PATEMAN, 1992). Falar de empoderamento das mulheres tem importância porque se discute a inclusão e a exclusão delas no mundo público/político, e porque é fundamental a sua participação na complexa arena do poder público, no conjunto da vida social e econômica, porque a desigualdade de gênero segue perene, e porque devemos perguntar sempre como reverter a complexa relação das mulheres com o poder, que, por centenas de anos, as tem marginalizado tanto no plano formal institucional como no cultural e simbólico. Corroboramos com o ponto de vista de que, particularmente em um país como o Brasil, não é possível nos esquecermos da desigualdade e nos voltarmos apenas para as diferenças entre os indivíduos. Não cabe, portanto, abandonarmos a ideia de totalidade (GARCÍA CANCLINI, 1990), considerada "concreta, inclusiva e macroscópica, de máxima complexidade, constituída por totalidades de menor complexidade" (NETTO, 2009, p. 56).

Atualmente, apesar dos avanços da inclusão do enfoque de gênero nas agendas públicas em nível mundial, particularmente no Brasil, com elevados índices de desigualdade as mulheres, em razão de seu gênero, continuam com barreiras de equidade, sofrendo violência, com dificuldade de aceder a recursos econômicos, educativos e espaços políticos de decisão. Os conceitos de poder e dominação patriarcal vêm sendo utilizados como base para uma explicação da subordinação feminina. As teorias do patriarcado, a partir da sociologia clássica de Marx Weber (1964) e Karl Marx (2009), intentam compreender as origens da dominação/exploração da mulher no trabalho como fundada na forma arcaica de dominação que é o patriarcalismo, definido como uma estrutura sobre as quais se assentam todas as sociedades contemporâneas. O patriarcado funda a estrutura da sociedade e recebe reforço institucional; nesse contexto, relacionamentos interpessoais e personalidade são marcados pela dominação e violência. O patriarcado, pois, é caracterizado por uma autoridade imposta institucionalmente, do homem sobre mulheres e filhos, no ambiente familiar, permeando toda organização da sociedade, da produção e do consumo, da política, à legislação e à cultura (CASTELLS, 1999).

As relações de gênero na sociedade patriarcal fazem parte da dinâmica social das desigualdades, as quais podem ser pautadas nas chamadas diferenças 'naturais' construídas socialmente entre os sexos masculino e feminino. Uma 
hierarquia é colocada como forma organizadora dos modelos classificatórios, como um modo de organizar o mundo, baseado no princípio do valor que confere significado às diferenças de valores de gêneros distintos. É preciso ficar atento para o peso da cultura patriarcal que poderá colocar mais ou menos empecilhos (assimetrias e segmentação do mercado, de setores e ocupações, divisão sexual do trabalho) ao acesso das mulheres à esfera pública e ao mercado de trabalho. Nessa linha de reflexão, preconiza-se que para desafiar a sua subordinação, as mulheres, primeiro têm que reconhecer a ideologia que legitima a dominação masculina, e, segundo, entender como se perpetua sua opressão. Esse reconhecimento questiona os valores e as atitudes que a maioria das mulheres vem internalizando em seus processos de socialização, desde crianças.

\section{METODOLOGIA}

O estudo se caracterizou como uma pesquisa qualitativa de natureza bibliográfica, na área das Ciências Sociais problematizando os elementos conceituais sobre gênero, patriarcado e empoderamento das mulheres em diálogo com a análise das condições de vida e relações de gênero que atravessam o cotidiano. Este tipo de metodologia compreendida como a busca de conhecimento científico já produzido relacionado ao tema proposto possibilitou a escolha de produções vigentes. Seguiu-se a análise e a interpretação à luz do referencial teórico e de conceitos principais definidos durante o estudo.

\section{O USO DO TERMO EMPODERAMENTO}

O termo empoderamento (empowerment) originou-se nos Estados Unidos durante os movimentos de direitos civis dos anos de 1960, generalizando-se em vários aspectos, em nível internacional, nacional e comunitário. No início foi liderado por mulheres feministas no campo do desenvolvimento e dos movimentos sociais das mulheres, em meados dos anos de 1970, e logo se ampliou aos estudos sobre comunidades; o termo passou também a nomear a cooperação para o desenvolvimento em agências como o Banco Mundial e chegou a ser parte das Metas do Milênio estabelecidas pela Organização das Nações Unidas (ONU) em 2000, com o apoio de 191 nações, que ficaram conhecidas como Objetivos de Desenvolvimento do Milênio (ODM). São eles: 1. Acabar com a fome e a miséria. 2. Oferecer educação básica de qualidade para todos. 3. Promover a igualdade entre 
os sexos e a autonomia das mulheres. 4. Reduzir a mortalidade infantil. 5. Melhorar a saúde das gestantes. 6. Combater a Aids, a malária e outras doenças. 7. Garantir qualidade de vida e respeito ao meio ambiente. 8. Estabelecer parcerias para o desenvolvimento (ORGANIZAÇÃO DAS NAÇÕES UNIDAS, 2000). Consta do objetivo 3: "Promover a equidade de gênero e o empoderamento", aí ocorrem tanto a ampliação do seu uso quanto um esforço para cumprir esse objetivo, em resposta à necessidade de gerar mudanças dentro das relações de poder entre os gêneros.

A partir de 2006, a ONU estipulou um nono objetivo para o Brasil: garantir que as melhorias obtidas na luta pelo cumprimento dos objetivos do milênio promovam igualdade de condições para brancos e negros. Tal meta foi batizada como Os objetivos do milênio sem o racismo, sendo levada em conta na análise dos resultados finais da campanha. Só seriam cumpridos os oito objetivos principais se, em 2015, brancos e negros estivessem em condições iguais (ORGANIZAÇÃO DAS NAÇÕES UNIDAS, 2015).

Desde meados dos anos de 1980 o termo empoderamento tem sido popular no campo do desenvolvimento, especialmente em referência a mulheres nos programas de base, sendo empregado usualmente em relação a termos como: bemestar, melhoramento na participação comunitária e alívio da pobreza e para descrever a meta de desenvolvimento e suas intervenções. A inserção do conceito empoderamento na agenda política tem como fonte de interação o feminismo e o conceito de 'educação popular' desenvolvido na América Latina nos anos de 1970 (WALTERS, 1991). Neste contexto, adverte-se sobre a preocupação da inserção do conceito de emancipação atribuído para as mulheres, de forma instrumentalizada, utilizado de uma maneira retórica e despolitizada.

Uma das contradições no debate acerca do termo empoderamento se expressa entre o individual e o coletivo, isto porque, no sentido individual, 0 empoderamento circunscreve-se ao sentido que os indivíduos o conferem. Para Magdalena León (1997) o empoderamento inclui a mudança individual e a ação coletiva para alterar os processos e estruturas que reproduzem a posição subordinada da mulher, deve ser priorizado como transformação de estruturas de subordinação, ou seja, como um processo de emancipação. Como primeira estratégia, devem-se responder as necessidades e demandas específicas das mulheres para sobreviver, para poder sair da pobreza. São demandas práticas: a luta pelo salário, pelo emprego, pela saúde, pela habitação, pelo colégio para os 
filhos, etc. A segunda estratégia refere-se àquelas necessidades e interesses que apontam a uma mudança fundamental nas relações desiguais de poder existentes entre os gêneros.

\section{EMPODERAMENTO COM A PERSPECTIVA DE GÊNERO}

Na década de 1990, o conceito de empoderamento com a perspectiva de gênero começou a ser utilizado por agências internacionais de cooperação, apresentando caráter polissêmico (para designar qualquer coisa que toma em conta as mulheres), e converteu-se em uma palavra da moda. Sustenta-se que o uso do termo empoderamento considerado como um conceito sociopolítico também trouxe a participação formal e o enfoque da conscientização, emancipação, requerendo a compreensão dos complexos fatores que geram a subordinação feminina. Nesse ponto, a subordinação de gênero e sua construção social foram prioridades nas análises feministas e da educação popular inspiradas na teoria da conscientização de Paulo Freire (1987), que ignorou totalmente a perspectiva de gênero, porém, mediante a sua influência gramsciana, acentuou a necessidade de mecanismos de participação das instituições da sociedade, com o fim de criar um sistema equitativo de gênero. Em coerência com a demanda de organismos internacionais, como a ONU, pela equidade de gênero como forma de reduzir os índices de pobreza e mortalidade, as organizações governamentais propugnaram pelo empoderamento das mulheres, em resposta às suas necessidades, à garantia de seus direitos e à sua reivindicação, para que possam participar de todos os setores sociais e gerar transformações em suas condições de vida.

As mulheres vêm assumindo um papel de provedoras e de chefias de família, sobretudo por deterem em suas mãos o poder aquisitivo e contribuírem, efetivamente, para o orçamento doméstico. No período de 2010-2014 no Brasil, o Instituto Brasileiro de Geografia e Estatística (IBGE, 2015) indica 67\% (11,4 milhões) de mulheres na condição de chefia familiar. Contudo, permanecem as assimetrias na divisão sexual do trabalho. Elas têm mais anos de estudo, se dividem entre o trabalho e os cuidados com a casa (desempenham dupla, tripla jornadas de trabalho), ganham menos e trabalham mais. Os dados de gênero divulgados pelo IBGE (2015) mostram que as brasileiras estão tendo filhos mais tarde e se tornando chefes de família em mais domicílios do país. Elas comandam $87 \%$ das famílias sem cônjuge e com filhos. Elza Berquó (2002, p.248) evidencia que desde o final do 
século XX esboça-se uma tendência à diminuição da hierarquia conjugal, conforme sinalizado por muitas famílias. Mesmo com a presença de marido ou companheiro, a mulher é frequentemente apontada como a principal provedora do domicílio.

Não se pode esquecer que, na realidade brasileira, tem-se um passado de padrões de relacionamentos autoritários, reforçados pela herança dos regimes militares, o que provavelmente contribui para dificultar a construção de práticas em que as relações democráticas se apresentem como características predominantes (CRUZ, 2005). Como sociedade caudatária da civilização europeia e, mais precisamente, como ex-colônia portuguesa, o Brasil estruturou seu modelo familiar nos moldes ditados pela cultura romano-cristã, ali recolhendo as bases para a construção de suas leis que regem as relações entre os sexos (LEITE, 1994). O lugar da mulher era a esfera privada, no âmbito doméstico da família. Na esfera pública, o poder caracterizava-se como eminentemente masculino. Então, desponta o discurso gerador de justificativas biológicas sobre a fragilidade feminina, necessárias à política sexual de separação das esferas pública e privada. Frise-se que essa análise exige a desconstrução de muitos significados vinculados à biologia, ao sexo, à natureza, ao gênero.

É importante destacar que o patriarcado não pode ser analisado como um domínio ideológico tendo como o lócus a reprodução de classe. Em outras palavras, existe uma estrutura patriarcal de produção, uma estrutura de classe e de cultura; as duas são coordenadas, não complementares e são entrelaçadas. Sua dinâmica interage; elas ajudam a estabilizar e a desestabilizar uma a outra e seus efeitos na vida de qualquer pessoa são condensados. O ponto essencial é que, como uma questão de fato, essa estrutura conjunta é a estrutura da formação da pessoa (CONNELL, 1993). Preconiza-se que o patriarcado - cultural, histórica e juridicamente construído na América Latina - tende a ser amenizado e superado à medida que a sociedade fortalece seu caráter democrático e busca transitar para a instauração de relações sociais de sexo/gênero mais justas. Conforme Manuel Castells (1999) ocorre o declínio das formas tradicionais de família patriarcal como base fundamental, condicionado por forças propulsoras como o crescimento da economia informacional, global, mudanças tecnológicas na reprodução da espécie e a luta das mulheres - denominada por ele de "movimento multifacetado" - causam impactos profundos nos mais variados segmentos da sociedade. 


\section{O EMPODERAMENTO: UMA NOVA CONCEPÇÃO DE PODER}

O empoderamento das mulheres, numa perspectiva mais ampla, pode transpor o âmbito doméstico e se consolidar em esferas públicas, na medida em que a participação delas é ativa em movimentos, conscientização na sociedade, atuação nas instâncias governamentais e também com a criação de organizações da sociedade civil (associações). Entende-se que nenhuma forma de controle é absoluta e, sendo assim, sempre haverá algum espaço, mesmo reduzido, que permitirá a existência de autonomia.

Para Nelly Stromquist (1997), uma plena definição de empoderamento deve incluir os componentes cognitivos, psicológicos, políticos e econômicos. O componente cognitivo faz referência à compreensão que têm as mulheres sobre suas condições de subordinação, assim como as causas desta nos níveis micro e macro da sociedade. A aquisição de novo conhecimento é necessária para criar um entendimento diferente das relações de gênero e abolir crenças antigas que estruturam representações de gênero. Também inclui conhecimento sobre a sexualidade que vai muito além de temas de planificação familiar. A área cognitiva ainda envolve o conhecimento das mulheres sobre os direitos jurídicos/legais, políticos e econômicos e corresponde à busca da igualdade.

O componente psicológico inclui o desenvolvimento de sentimentos que as mulheres podem colocar em prática em nível pessoal e social para melhorar sua condição. A autonomia dá ênfase à faceta psicológica do conceito de empoderamento, envolve o poder desde dentro para que as mulheres possam exercer qualquer poder sobre os outros segmentos da sociedade. Stromquist (1997) entende que o elemento psicológico precisa ser reforçado com o componente econômico, como forma de superar a subordinação econômica das mulheres, para que elas tenham capacidade de comprometer-se com a atividade produtiva que lhes dará algum ganho, grau de autonomia e oportunidade de ser empoderada. $O$ componente político do empoderamento supõe a habilidade para analisar o meio circundante em termos políticos e sociais; isto também significa a habilidade para organizar e mobilizar as mudanças sociais.

Nas análises tradicionais, o poder estava concentrado no Estado, centro regulador da sociedade. Karl Marx (2009) entendia o Estado como um aparato montado a favor das classes dominantes, como um órgão repressivo destas para 
manter a existência da propriedade privada. Max Weber (1964) concebia o Estado como detentor do monopólio do uso da força através de seu aparato armado. Já Émile Durkheim (2002) compreendia o Estado como o cérebro de um organismo. Todas essas análises entendem o poder como algo pairando sobre os indivíduos, como se estes não fossem responsáveis por ele. Em uma perspectiva microfoucaultiana, o poder é assimilado, não como uma entidade ou algo que tenha um local determinado para acontecer, mas sim como estando em toda parte, pois provém de todos os lugares, tem capilaridade.

$\mathrm{Na}$ perspectiva foucaultiana, quanto mais escondido o poder estiver, mais eficaz o será, pois, os dominados não perceberão a relação de dominação e assim não resistirão. Particularmente para as mulheres, o foco do poder pode ser mudado, possibilitando que as assimetrias e desvantagens historicamente produzidas sejam hierarquicamente modificadas pelo empoderamento. É importante desafiar a ideologia patriarcal e habilitar as mulheres, de modo que possam aceder tanto aos recursos materiais como a informações e exercer controle sobre eles.

Nesta perspectiva, falar do conceito de gênero significa falar de poder, de uma categoria de análise sobre a condição, situação e diferenças entre homens e mulheres. O gênero é um termo científico que se desenvolveu inicialmente dentro da teoria feminista, e tem recebido distintas definições. Gaylle Rubin (1993) assinala que o gênero se refere à construção cultural da diferença sexual, pois implica necessariamente as relações entre os sexos. O 'sistema sexo/gênero' é um conjunto de condições mediante as quais se satisfazem estas necessidades sexuais transformadas. Na definição posterior de Joan Scott (1995. p. 71), o gênero aparece como "[...] um elemento constitutivo das relações sociais que se baseiam nas diferenças entre os sexos [...]" e "[...] uma forma primária das relações de poder". Ambas as autoras se referem à diferença sexual como se esta antecedesse ao gênero. A definição de Scott (1995) incorpora elementos novos, como o reconhecimento da transversalidade de gênero e a atenção à influência dos 'saberes e discursos' em relação ao gênero - e este aparece como uma construção cultural sobre a base do sexual.

Contudo, Judith Butler ${ }^{4}$ (1998) questiona o sujeito do feminismo e propõe uma versão não essencialista e performativa do gênero, constituído por um sujeito que se

${ }^{4}$ Continua a marcar não só a investigação acadêmica, e os movimentos feministas e LGBTQI (Lésbicas, Gays, Bissexuais, Transgênero, Queer e Intersexo), como também a criação artística. 
apropria dele; as identidades femininas e masculinas são produtos performativos que se realizam em um contexto cultural. Esta autora mina a distinção entre gênero e sexo, afirma que o próprio corpo é já uma construção cultural, na medida em que os discursos sobre o corpo, a sexualidade e o gênero definem o que é considerado corpo, os seus limites e o seu significado. Para Butler (1998), o gênero não é binário senão múltiplo, e ocorre de acordo com as condições de cada mulher e de cada homem, aparece como o meio discursivo/cultural mediante o qual se produz uma 'natureza sexuada' ou um 'sexo natural', embora os sexos pareçam ser binários, em sua morfologia e constituição, isto não ocorre. As pessoas são 'transgêneros', cada vez mais, transcendem/transgridem a atribuição de gênero conforme seu sexo ao nascer. A forma de resistir às normas de gênero faz-se por via de performances subversivas de gênero, que desestabilizam esta equação sexo/gênero/desejo; por exemplo, performances em que o sexo e o gênero não correspondam, ou em que a hegemonia da heterossexualidade é contestada ${ }^{5}$.

O desenvolvimento histórico do conceito de gênero, apresentado de forma muito sucinta, tem contribuído não apenas para a emancipação e direitos das mulheres, mas também de grupos marginalizados, tais como lésbicas, gays, bissexuais, pessoas transgêneras e pessoas intersexuais (LGBTI). As concepções culturais acerca do gênero constroem, então, nossas ideias sobre o sexo, ao mesmo tempo nos fazem crer que este é 'prediscursivo', ou prévio à cultura e considerado como 'natural'. A partir dessas reflexões, podemos esboçar uma nova definição de gênero como um sistema de saberes, discursos, práticas sociais e relações de poder que, em uma época, e em um contexto determinado, estrutura os conteúdos específicos das representações do corpo sexuado, da sexualidade e das diferenças físicas, socioeconômicas, culturais e políticas entre os sexos (e as relações entre eles). A análise das relações sociais de gênero fundamenta-se na compreensão de que as distinções entre mulheres e homens são resultado de construções culturais, são produtos da cultura e não decorrem de dados biológicos.

Desafia o pressuposto de que existe uma correspondência entre um sexo específico, uma determinada identidade de gênero e um desejo pelo "sexo oposto". Butler concebe "gênero não é uma categoria ontológica, mas que se faz", que "se constrói”, que é, em última análise, performance. 5 Por meio das performances, podemos observar como os gêneros são produzidos e reconhecidos como corpos dóceis e a ficção do binarismo hegemônico de gênero. O modelo expressivo de identidade se torna o centro das atenções desconstrutivas de Judith Butler que propõe a teoria da performatividade de gênero (e da identidade em geral). 
Corroborando com Cecília Sardenberg (1998), o conceito de gênero não substitui a categoria mulher, tampouco torna irrelevante pesquisas/reflexões sobre mulheres como um grupo social discriminado. Ao contrário, permite que se pense essa categoria como uma construção social historicamente específica e como é legitimada a situação de discriminação, exploração e subordinação das mulheres. Gênero dá conta da diversidade da condição/experiência feminina em sociedades distintas, no tempo e espaço, possibilita pensar as relações entre os sexos no plano das relações sociais de gênero (entre mulheres e homens, bem como entre mulheres e mulheres e entre homens e homens). É preciso ancorar as relações pessoais em seus contextos e estudar as condições sociais de produção dos discursos.

\section{O EMPODERAMENTO E RECONHECIMENTO DAS MULHERES}

O empoderamento das mulheres envolve igualmente o reconhecimento como uma dimensão do empoderamento desde a relação das mulheres com o seu entorno/contexto, com o marco dos direitos humanos e com o seu grupo social. Para Axel Honneth (2003), a luta pelo reconhecimento implica também a obtenção de confirmação intersubjetiva por parte de cada sujeito, e o fato de ambos se apoiarem no conceito de solidariedade (complementado por valores e objetivos comuns, resultantes de experiência de interações passadas), ou seja, na expressão coletiva por direitos (articulação das necessidades sociais). O autor propõe formas de reconhecimento: de laços emocionais, de reconhecimento jurídico e dos direitos e da adesão solidária. A questão do reconhecimento, na condição de parte inseparável da percepção da autocompreensão das mulheres, dos movimentos sociais, e de toda a vida social em si, é um processo social permanente que se dá em relação aos outros, no marco das relações com eles e através dessas relações (HONNETH, 2003).

Compreende-se que os processos de empoderamento se constituem em modos de subjetivação, que aludem na perspectiva foucaultiana às formas de configuração dos sujeitos, aos procedimentos e processos pelos quais o sujeito existe e se constitui. Em outras palavras, Foucault (2001) chama de subjetivação o "[...] processo pelo qual se obtém a constituição de um sujeito, mas exatamente de uma subjetividade, que evidentemente não é senão uma das possibilidades dadas de organização de uma consciência de si”. (FOUCAULT, 2001, p.39). 
Tal como Foucault (2001), em sua análise do processo de subjetivação, essas práticas não são nem alheias nem impostas ao sujeito, pois o mesmo as apropria através de suas experiências, nas formas como este faz e age consigo mesmo. A proposta de subjetivação que subjaz às de empoderamento das mulheres deve ser direcionada por discursos abrangendo as dimensões dos direitos humanos, baseada na igualdade entre os seres humanos e na garantia de que todos tenham as mesmas oportunidades e uma vida digna; e a dimensão de gênero, uma ferramenta conceitual centrada no discurso dos direitos humanos, na qual se pensa como as mulheres - historicamente - têm sido excluídas, através da negação de seus direitos. A luta das mulheres por igualdade questiona o conceito de luta social, sua ligação com 'sentimentos morais de injustiça', a construção de uma forma de subjetividade ligada ao poder, à autonomia e à participação política; propõe uma prática para que as mulheres produzam a si mesmas, na qual cada uma se insere e configura de uma maneira particular.

\section{A DIMENSÃO DA EDUCAÇÃO NO EMPODERAMENTO}

O respeito à diversidade nas instituições de ensino torna-se essencial para o desenvolvimento social - entendido nos termos estabelecidos pela Declaração de Copenhagen, consiste no preparo dos estudantes para trabalhar proativamente em seus contextos sociais e políticos, influenciando positivamente os seus ambientes e exercitando responsabilidades. Inclusive, os novos movimentos sociais reivindicam que a educação considere, nos seus diversos níveis e modalidades, a relação entre diversidade e desigualdade. Para Boaventura Santos (2006, p.316) "temos o direito a ser iguais sempre que a diferença nos inferioriza; temos o direito a ser diferentes sempre que a igualdade nos descaracteriza". A ideia básica do movimento de mulheres (de diferentes movimentos de mulheres) centra-se na perspectiva de liberdade e igualdade de oportunidades entre os sexos na família e na sociedade.

$O$ reconhecimento da diferença e desigualdade centra-se em versões emancipatórias do multiculturalismo, com vista a dar conta de um conjunto de políticas de reconhecimento do direito à diferença e da coexistência ou construção de uma vida em comum. (SANTOS, 2003). A problemática do empoderamento e da discriminação é, certamente, complexa, e precisa ser trabalhada com base em uma dimensão multidimensional. As explicações centradas na cultura, na política e na ideologia assumem, hoje, papel de destaque no cenário social, adicionando-se às 
análises dos fenômenos complexos e contraditórios que se desenvolvem no nível econômico. A 'centralidade da cultura' no cenário contemporâneo é ressaltada por Stuart Hall (1997) no seu papel constitutivo em todos os aspectos da vida social contemporânea, no nível do microcosmo, tornando-se elemento-chave no modo como o cotidiano é configurado e modificado. Também Michael Apple (1999) entende importante valorizar e reconhecer a esfera cultural sem desconsiderar a força do capitalismo, o caráter determinante das relações de produção e do poder da classe social.

A desigualdade educacional é uma das grandes infrações dos direitos das mulheres e meninas e também uma barreira importante ao desenvolvimento social e econômico. Por isso, a educação formal tem sido identificada por muitos como uma poderosa ferramenta de mudança, constitui um dado que suscita formas de melhorar as condições das mulheres, contribui substancialmente ao melhoramento da identidade de gênero através de mudanças nos estereótipos sexuais nos textos (ideias pré-concebidas baseadas em diferenças do papel do homem e da mulher), promoção de identidades de gênero positivas por meio do currículo e formação docente com sensibilidade de gênero, um serviço de orientação e assessoria não sexista. O empoderamento é um processo urgente de despatriarcalização, de construção de estratégias de destradicionalização do Estado. A dinâmica de aproximação dos movimentos feministas com o Estado é recente. Isso porque, historicamente, as feministas de diversos matizes e orientações teóricas criticam e repudiam o patriarcado público que o modelo de Estado e o capitalismo exercitam. Segmentos do movimento feminista brasileiro nestas últimas décadas (1976 a 2006) se empenharam, em várias estratégias de luta, inicialmente demandando ações do Estado tanto pela via institucional-legislativa quanto pela via jurídica, a fim de coibir, por exemplo, a 'violência contra a mulher' com a criação da Delegacia Especializada de Atendimento à Mulher (DEAM) em 1985. (BANDEIRA, 2009).

Por meio da teoria da interseccionalidade é possível verificar "as formas como as políticas específicas geram opressões que fluem ao longo de tais eixos, da intersecção de raça, gênero, classe ou nação, constituindo-se dinâmicos ou ativos do desempoderamento" (CRENSHAW, 2002, p. 177). Segundo Kimberlé Crenshaw (2002) a interseccionalidade é uma conceituação do problema que busca capturar as consequências estruturais e dinâmicas da interação entre dois ou mais eixos de subordinação de raças, etnias, classes e outras. Ela trata especificamente da forma 
pela qual o racismo, o patriarcalismo, a opressão de classe e outros sistemas discriminatórios criam desigualdades. A interseccionalidade se refere a modos singulares de intersectar opressões, permite ampliar e tornar mais complexo o olhar sobre a produção de desigualdades em contextos específicos e fazer uma análise mais condizente com a realidade, por exemplo, permite captar as relações de poder na vida social e seus impactos nas experiências cotidianas dos sujeitos. Neste sentido, interseccionalidade constitui-se em ferramenta teórico-metodológica fundamental para ativistas e teóricas feministas comprometidas com análises que desvelem os processos de interação entre relações de poder e categorias como classe, gênero e raça em contextos individuais, práticas coletivas e arranjos culturais/institucionais.

O empoderamento deverá centrar-se nas mulheres adultas e também na educação não formal: primeiro, como adultas elas têm tido muitas experiências de subordinação e isto lhes permite conhecer muito bem esse problema, apesar de não reconhecê-lo como tal; e segundo, a transformação dessas mulheres é fundamental para romper a reprodução intergeracional da autoridade patriarcal (STROMQUIST, 1997). Estes elementos são, antecedentes cruciais para o empoderamento, no empoderamento mesmo. Ainda que o nível de escolaridade seja maior e favorável às mulheres, não garante a elas igualdade de gênero no mercado de trabalho, mesmo que a diferença entre o salário feminino e o masculino tenha diminuído.

Um melhor nível educacional possibilita o aumento do potencial de geração de renda, da autonomia, do controle de sua fertilidade e maior participação política na vida pública e estes são aspectos essenciais para mudar a vida das mulheres. Conforme Helena Hirata (2002) o acirramento das desigualdades sociais pode ser observado na participação no mercado de trabalho, especificamente no continente latino-americano, o que justifica a urgência de discussões que possibilitem um maior entendimento dessa realidade. Em todas as áreas do mercado de trabalho existe segregação de gênero, considerando as diferenças regionais e culturais. Para a autora essa segregação gera a divisão sexual do trabalho, a partir do momento que se define o que é função de mulher e de homem, destaca que no paradigma de produção atual a acentuada divisão sexual $^{6}$ do trabalho tem gerado e reforçado

\footnotetext{
${ }^{6}$ Do ponto de vista histórico observa-se que a estruturação atual da divisão sexual do trabalho (trabalho assalariado/doméstico; fábrica/escritório/família) surgiu simultaneamente ao capitalismo, e, que a relação assalariada não poderia estabelecer-se na ausência do trabalho doméstico.
} 
diversas diferenciações nos contratos de trabalho, no processo de qualificação como no de requalificação, sob o enfoque das teorias da dominação, na política salarial e de treinamento, nas formas de inserção e ascensão.

A segmentação entre os homens e as mulheres é parte integrante da divisão sexual do trabalho. Pesquisa do IBGE (2010) revela que, em média, há 10,6 milhões de mulheres na ativa, sendo 9,6 milhões delas ocupadas e 1,1 milhão desempregadas, considerando uma inatividade de mulheres estimada em 11,3 milhões. As mulheres fazem $52 \%$ de todo o trabalho no mundo, mas ganham, em média, $24 \%$ a menos do que os homens. A tradição cultural que definiu o homem como provedor da família e, portanto, responsável por trabalhar fora e ganhar o seu sustento, e a mulher como responsável pelos filhos e pela execução dos serviços domésticos sempre foi um fato determinante na inserção das mulheres no mercado de trabalho.

\section{PARA CONCLUIR}

Podemos admitir que as mulheres têm sido objeto do poder dominador na sociedade, particularmente do poder invisível. Por isso, se diz que estamos em situação de desempoderadas, porém, os poderes que temos tido são limitados, porque socialmente não são reconhecidos como tais. São poderes do privado, do doméstico, e em grande medida do familiar. $O$ poder não é dado às mulheres porque elas não têm o mesmo reconhecimento social que têm basicamente, atribuído ao domínio dos homens que, fundamentalmente, estão na esfera pública.

A diversidade de gênero, entendida como construção histórica, social, cultural e política das diferenças, realiza-se em meio às relações de poder e ao crescimento das desigualdades e da crise econômica que se acentuam no contexto nacional e internacional. Neste contexto, se propõem particularmente às mulheres novos olhares, ações coletivas para a mudança, para a democracia paritária e justiça de gênero, mediante uma participação em nível global, regional, nacional, local e comunitário, na família, na política, na economia e no social dos homens e das mulheres. É preciso levar em conta as relações de poder entre homens e mulheres, e, desta maneira, buscar solucionar não somente condições concretas materiais das mulheres, senão também mudar as relações sociais de gênero na sociedade, construindo democracias com equidade de gênero. 


\title{
REFLECTIONS ON POWER MEASURED BY THE EMPOWERMENT OF WOMEN AS POLITICAL SUBJECTS
}

\begin{abstract}
:
This article aims to reflect on the empowerment of women as political subjects, a fundamental element for their emancipation and active participation in society. In order to reach the proposed objective, a qualitative bibliographical research was developed on different perspectives about the concepts of gender, patriarchy and empowerment of women. Empowerment involves a political process to generate understanding of the complex factors that create subordination/exclusion of women from the public/political world and stimulate awareness of reformulation/deconstruction of society's current political and social apparatuses. In conclusion, we state there is a need to take into account the power relations between men and women, and thus seek to solve not only concrete material conditions for women, but also to change the social relations of gender in society, building democracies with gender equality.
\end{abstract}

Keywords: Power. Empowerment. Gender. Recognition. Equity.

\section{REFLEXIONES SOBRE EL PODER MEDIADAS POR EL EMPODERAMIENTO DE LAS MUJERES EN LA CONDICIÓN DE SUJETO POLÍTICO}

\section{Resumen:}

Este artículo tiene como objetivo reflexionar sobre el empoderamiento de las mujeres en la condición de sujeto político, elemento fundamental para su emancipación y participación activa en la sociedad. Con miras a alcanzar el objetivo propuesto, se desarrolló una investigación cualitativa de naturaleza bibliográfica en diálogo con vertientes de los conceptos de género, patriarcado y empoderamiento de las mujeres. El empoderamiento implica un proceso político para generar comprensión de los complejos factores que crean subordinación/exclusión de las mujeres del mundo público/político y engendrar conciencia sobre la reformulación/deconstrucción de los actuales esquemas políticos y sociales de la sociedad. Captamos, pues, que hay que tener en cuenta las relaciones de poder entre hombres y mujeres, y, de esta manera, buscar solucionar no sólo condiciones concretas materiales de las mujeres, sino también cambiar las relaciones sociales de género en la sociedad, construyendo democracias con equidad de género.

Palabras Clave: Poder. Empoderamiento. Género. Reconocimiento. Equidad. 


\section{REFERÊNCIAS}

APPLE, M. W. Power, meaning and identity: essays in critical educational studies. New York: Peter Lang, 1999.

BANDEIRA, L. Três décadas de resistência feminista contra o sexismo e a violência feminina no Brasil: 1976 a 2006. Sociedade e Estado, Brasília, v. 24, n. 2, maio/ago., 2009, p.401-438.

BERQUÓ, E. Arranjos familiares no Brasil: uma visão demográfica. In: SCHWARCZ, L.M. (Org.). História da vida privada no Brasil. Contrastes da intimidade contemporânea. São Paulo: Companhia das Letras, 2002.

BUTLER, J. Problemas de gênero: feminismo e subversão da identidade. Rio de Janeiro: Civilização Brasileira, 1998.

CASTELLS, M. O poder da identidade. A era da informação: economia, sociedade e cultura. São Paulo: Paz e Terra, 1999.

CONNELL, R. W. Schools and social justice. Montréal: Our Schools/Our Selves Education Foundation, 1993.

CRENSHAW, K. Documento para o Encontro de Especialistas em Aspectos da Discriminação Racial Relativos ao Gênero. Revista Estudos Feministas, Florianópolis, v. 10, n. 1, jan., 2002, p.171-188. Disponível em: $<$ http://www.scielo.br/scielo.php?script=sci arttext\&pid=S0104026X2002000100011\&lng=pt\&nrm=iso $>$. Acesso em: 9 jan. 2018. http://dx.doi.org/10.1590/S0104-026X2002000100011

CRUZ, M. H. S. Trabalho, gênero e cidadania: tradição, modernidade. Aracaju: Editora UFS, 2005.

DURKHEIM, É. D. Lições de sociologia: a moral, o direito e o Estado. São Paulo: Martins Fontes, 2002.

FOUCAULT, M. Microfisica do poder. 16. ed. Rio de Janeiro: Graal, 2001.

FOUCAULT, M. A hermenêutica do sujeito. São Paulo: Martins Fontes, 2006. 
FREIRE, P. Pedagogia do oprimido. Rio de Janeiro: Paz e Terra, 1987.

GARCIIA CANCLINI, N. Culturas híbridas: estratégias para entrar y salir de la modernidad. México: Grijalbo.1990.

HALL, S. A centralidade da cultura: notas sobre as revoluções de nosso tempo.

Educação \& Realidade, v. 22, n. 2, 1997, p.15-46.

HIRATA, H. Nova divisão sexual do trabalho? Um olhar voltado para a empresa e a sociedade. São Paulo: Boitempo, 2002.

HONNETH, A. Luta pelo reconhecimento: para uma gramática moral dos conflitos sociais. Tradução Luiz Repa. São Paulo: Editora 34, Edição brasileira, 2003.

INSTITUTO BRASILEIRO DE GEOGRAFIA E ESTATÍSTICA (IBGE). Pesquisa Mensal de Emprego (PME) (2010). Disponível em: <http://www.ibge.gov.br/ home/estatistica/ indicadores/trabalhoerendimento/pme nova/Mulher Mercado Trabalho Perg Resp. pdf>. Acesso em: 2 ago. 2017.

INSTITUTO BRASILEIRO DE GEOGRAFIA E ESTATÍSTICA (IBGE). Síntese de indicadores sociais. (2015). Disponível em:

<www.sof.org.br/2015/06/12/publicacao-estatisticas-de-genero $>$. Acesso em: 7 out. 2017.

LEITE, C. L. de P. Mulheres: muito além do teto de vidro. São Paulo: Atlas, 1994.

LEÓN, M. (Org.). Poder y empoderamiento de las mujeres. Santafé de Bogotá: Tercer Mundo y UN Facultad de Ciencias Humanas, 1997. Disponível em:

<https://issuu.com/renejaimez/docs/el-empoderamiento-de-las-mujeres>. Acesso em: 17 nov. 2017.

MARX, K. Contribuição à Crítica da Economia Política. Expressão Popular: São Paulo, 2009.

NETTO, J. P. Introdução ao Método da Teoria Social. In: Serviço Social: Direitos Sociais e Competências Profissionais. UNB: Ed. CFESS/ABEPSS, 2009, p.667-700. 
ORGANIZAÇÃO DAS NAÇÕES UNIDAS (ONU). Assembléia do Milênio.

Aprovada na Cimeira do Milénio - realizada de 6 a 8 de Setembro de 2000, em Nova lorque. Disponível em: <https://www.unric.org/html/portuguese/uninfo/DecdoMil.pdf>. Acesso em: 16 out. 2017.

ORGANIZAÇÃO DAS NAÇÕES UNIDAS (ONU). Objetivos de Desenvolvimento do Milênio. Relatório Nacional de Acompanhamento e Objetivos de Desenvolvimento do Milênio. Relatório Nacional de Acompanhamento 2015. Nações Unidas no Brasil. Brasília: Ipea. Disponível em:

<http://www.un.org/en/development/desa/policy/mdg gap/index.shtm>. Acesso em: 13 set. 2017.

PATEMAN, C. Participação e teoria democrática. Rio de Janeiro: Paz e Terra, 1992.

RUBIN, G. O tráfico de mulheres. Notas sobre a economia política do sexo. Tradução de Cristine Rufino Dabat. Recife: SOS Corpo, 1993 [1975].

SANTOS, B. de S. Reconhecer para libertar. Rio de Janeiro: Civilização Brasileira, 2003.

SANTOS, B. de S. A construção cultural da igualdade e da diferença. In: SANTOS, B. de S. A gramática do tempo. São Paulo: Cortez, 2006, p. 270-316.

SARDENBERG, C. M. B. O enfoque de gênero: fundamentos teóricos e aspectos práticos. Salvador: Ed. NEIM/UFBA, 1998.

SCOTT, J. W. Gênero: uma categoria útil para análise histórica. Educação e Realidade. Porto Alegre, v. 16, n. 2, jul./dez., 1995.

STROMQUIST, N. La busqueda del empoderamento: em qué puede contribuir el campo de la educación. In: LEÓN, M. (Org.). Poder y empoderamiento de las mujeres. Santafé de Bogotá: Tercer Mundo y UN Facultad de Ciencias Humanas, 1997. Disponível em: <https://issuu.com/renejaimez/docs/el-empoderamiento-de-lasmujeres>. Acesso em: 03 mar. 2017.

WALTERS, S. Her words on his lips: gender and popular educations in South Africa. ASPBAE, Courier, v. 52, n. 17,1991.

WEBER, M. Economia y sociedade. México: Fondo de Cultura Economica, 1964. 